\title{
Hierarchical Formation of Fibrillar and Lamellar Self-Assemblies from Guanosine-Based Motifs
}

\author{
Paolo Neviani, ${ }^{1}$ Dominique Sarazin, ${ }^{2}$ Marc Schmutz, ${ }^{2}$ Christian Blanck, ${ }^{2}$ \\ Nicolas Giuseppone, ${ }^{2,3}$ and Gian Piero Spada ${ }^{1}$ \\ ${ }^{1}$ Dipartimento di Chimica Organica “A. Mangini”, Alma Mater Studiorum-Università di Bologna, Via San Giacomo 11, \\ 40126 Bologna, Italy \\ ${ }^{2}$ Centre National de la Recherche Scientifique, Institut Charles Sadron, Université de Strasbourg, 23 Rue du Loess, BP 84087, \\ 67034 Strasbourg cedex 2, France \\ ${ }^{3}$ SAMS Research Group, icFRC, Centre National de la Recherche Scientifique, Université de Strasbourg, 23 Rue du Loess, \\ BP 84087, 67034 Strasbourg cedex 2, France
}

Correspondence should be addressed to Nicolas Giuseppone, giuseppone@unistra.fr and Gian Piero Spada, gianpiero.spada@unibo.it

Received 1 February 2010; Revised 7 April 2010; Accepted 27 May 2010

Academic Editor: Lea Spindler

Copyright (๑) 2010 Paolo Neviani et al. This is an open access article distributed under the Creative Commons Attribution License, which permits unrestricted use, distribution, and reproduction in any medium, provided the original work is properly cited.

Here we investigate the supramolecular polymerizations of two lipophilic guanosine derivatives in chloroform by light scattering technique and TEM experiments. The obtained data reveal the presence of several levels of organization due to the hierarchical self-assembly of the guanosine units in ribbons that in turn aggregate in fibrillar or lamellar soft structures. The elucidation of these structures furnishes an explanation to the physical behaviour of guanosine units which display organogelator properties.

\section{Introduction}

Supramolecular self-assembly represents a key technology for the spontaneous construction of nanoarchitectures and for the fabrication of materials with enhanced physical and chemical properties [1-4]. In addition, a significant asset of supramolecular self-assemblies rests on their reversible formation, thanks to the kinetic lability of their noncovalent interactions. This dynamic nature can be exploited for the development of "self-healing" and "smart" materials towards the tuning of their functional properties upon various external factors [5-8]. One particular intriguing objective in the field is to reach a high level of control over the shape and size of the supramolecular architectures, in order to produce well-defined functional nanostructures by rational design [9]. In this direction, many investigations have been pursued toward the construction of self-assembled objects from numerous low-molecular weight scaffolds [10-18], for instance, by exploiting multiple directional hydrogenbonding interactions. In particular, nucleobases have been used as supramolecular synthons as a result of their efficiency to code for noncovalent interaction motifs [19]. Among nucleobases, guanine represents the most versatile one, because of its different $\mathrm{H}$-bond donor $\left(\mathrm{N}^{1} \mathrm{H}\right.$ and $\left.\mathrm{N}^{2} \mathrm{H}\right)$ and acceptor sites $\left(\mathrm{O}^{6}, \mathrm{~N}^{3}\right.$, and $\left.\mathrm{N}^{7}\right)$ which display selfcomplementary patterns of interactions. Interestingly, and depending on the environmental conditions, guanosine derivatives can form various types of structures. Most of the supramolecular architectures reported so far from guanosine derivatives require the presence of a cation (alkali metal, earth-alkali, or lanthanide ions) [20-31] which stabilizes, via dipole-ion interactions, the macrocyclic G-quartet that can, in turn, stack in columnar G-quadruplex arrangements (Figure 1(a)). In addition, guanosine can polymerize via hydrogen bonding to give a variety of supramolecular networks including linear ribbons such as A- and B-types (Figures 1(b) and 1(c)). 


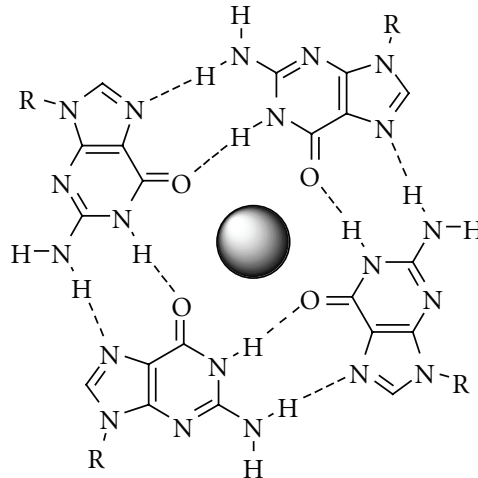

(a)

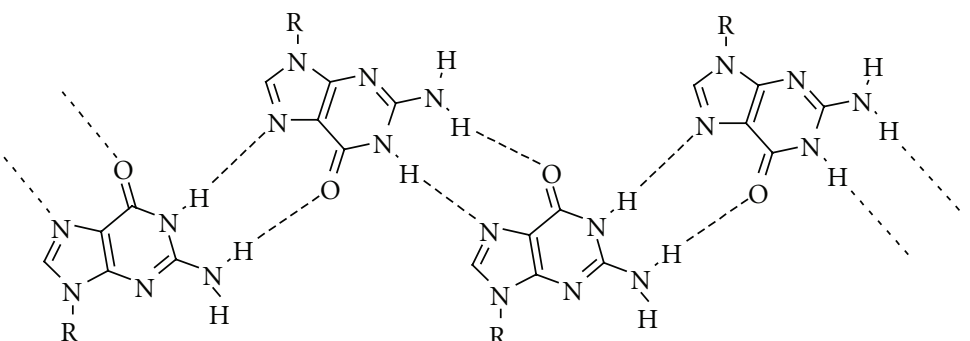

(b)

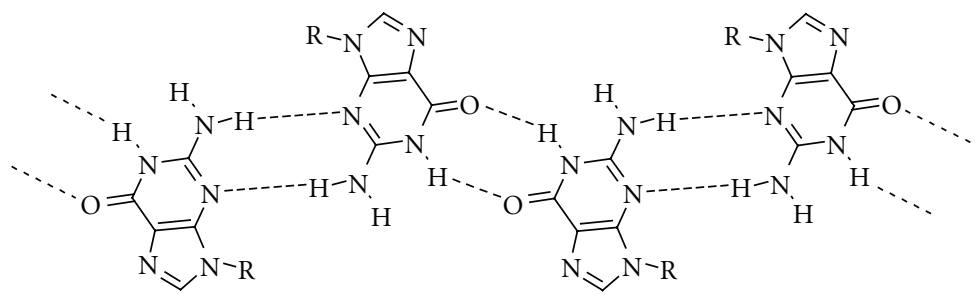

(c)

FIgURE 1: (a) G-quartet structure (the sphere indicates the central cation), (b) A-type ribbon, and (c) B-type ribbon.

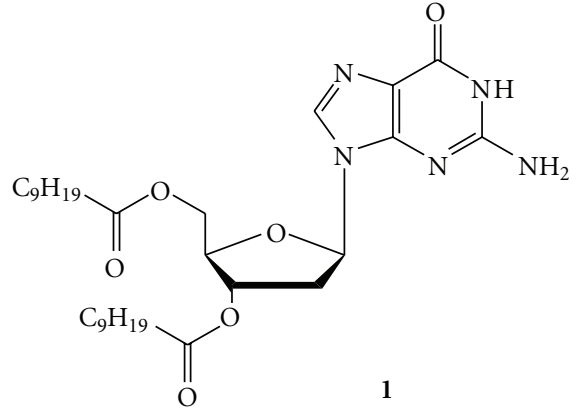

(a)<smiles>CCCCC(=O)OCC1O[C@@H]2OC(C)(C)O[C@@H]1[C@H]1OC(C)(C)OC21</smiles>

(b)

FIgURE 2: Structures of the two guanosine derivatives 1 and 2.

This complex supramolecular behaviour confers to the guanine-guanine interactions their upper interest among all the homonucleobases studied $[20,32]$. They have been subjected to intense investigations in various areas ranging from structural biology and medicinal chemistry-guanine-rich sequences are abundant in telomeric ends of chromosomes and promoter regions of DNA and are capable of forming G-quartet based structures [33-35] — to material science and nanotechnology [36, 37].

In 1998, it was reported [38] that, even in the absence of metal cations, lipophilic guanosine derivative $\mathbf{1}$ (Figure 2) is able to self-assemble in ribbon-like structures leading to the formation of a lyotropic liquid crystalline phase [39]. In the following years, the structures of the ribbons obtained from different guanosine derivatives have been characterized in solution (by NMR and ESI-MS), in the solid state (by X-ray diffraction and NMR), and at graphite-solution interface (by STM) [40-46]. Two different types of ribbons, with different patterns of hydrogen bonds, have been resolved in solution. The first species (ribbon-A, Figure 1(b)) is characterised by $\mathrm{N}^{2} \mathrm{H} \cdots \mathrm{O}^{6}$ and $\mathrm{N}^{1} \mathrm{H}^{\cdots \cdots} \mathrm{N}^{7}$ hydrogen bonds, and the second one (ribbon-B, Figure $1(\mathrm{c})$ ) by $\mathrm{N}^{1} \mathrm{H}^{\cdots} \mathrm{O}^{6}$ and $\mathrm{N}^{2} \mathrm{H}^{\cdots \cdots} \mathrm{N}^{3}$ hydrogen bonds. In the case of $\mathbf{1}$, ribbon-A is detected in anhydrous chloroform solutions $\left(c>10^{-2} \mathrm{M}\right)$ soon after dissolving the polycrystalline powder but subsequently undergoes a structural transition towards a thermodynamically more stable ribbon-B [40]. Interestingly, in the case of the closely related chemical structure of $\mathbf{2}$, only ribbon-B has been detected in chloroform solution (even soon after dissolution) [41]. For derivative $\mathbf{1}$, the critical concentration for the formation of the gel-like phase was measured $\geq 0.596 \mathrm{M}$ in chloroform, and for derivative $2 \geq 0.125 \mathrm{M}$ in the same solvent. 
In both ribbon-like polymers $\mathrm{A}$ and $\mathrm{B}$, the glycosidic bond adopts an anti conformation [42-46]. However, the two ribbons possess a different symmetry and, as a consequence, while ribbon-A does present a permanent dipole moment, it is not the case for ribbon-B. This feature has been exploited in organic electronic prototype devices [47-49], and more generally, linear ribbons from guanosine derivatives are considered as potential scaffolds for functional materials [50-54]. Although the formations of the linear ribbons and their $\mathrm{H}$-bonding patterns have been demonstrated in solution $[40,41]$ (as well as in the crystal state and on graphite surface), only very few investigations have been performed so far toward the determination of the length of these supramolecular polymers, as well as on their possible hierarchical self-assemblies in higher scale structures. NMR spectroscopic indications of the supramolecular polymerisation only come from the shifting and broadening of the resonance signals upon concentration of the solution. In addition, the observation of negative enhancements (or positive cross-peaks) in NOE (or NOESY) experiments indicates that guanosine derivatives behave as large molecules with $M_{W}>1000\left(\omega \tau_{\mathrm{c}}>1\right)$ [38-40].

In this paper we report on the investigation of the supramolecular polymerisation of $\mathbf{1}$ and $\mathbf{2}$ in chloroform by using light scattering technique as well as transmission electronic microscopy (TEM). This line of studies reveals the formation of supramolecular polymers with high molecular weights that produce hierarchical structuring of very soft self-assemblies displaying either fibrillar (1) or lamellar (2) organizations.

\section{Results and Discussion}

2.1. Static Light Scattering. The multiangle laser light scattering is the common technique $[55,56]$ for determining the shape of the polymers through the mean square radius of gyration $\left\langle R_{g}\right\rangle_{z}$ and their structure through the particle scattering factor $P_{Z}(q)$, the molecular weight $M_{W}$, and the second virial coefficient $A_{2}$. Theory took great interests long time ago giving statistical sense to these parameters [55-61]. When $A_{2}$ is near zero and solutions considered as athermal according to general polymer theories [61] one may deal with the apparent molecular weight $M_{w \text {,app }}$ and use the so-called statistical dimensions determined at discrete concentrations $[59,60]$ instead of the one extrapolated at $c \rightarrow 0$. Looking at the variation of $M_{w \text {,app }}$ versus concentration or temperature allows equilibrium constant $K_{0}$ to be evaluated which open fields to dynamics of the scaffolds and to their assembly ability. The form factor $P_{Z}(q)$ may be also useful to determine structural changes of the objects during the diffusion process of elementary unimers $[59,60]$. The form factor may derive from calculations especially when the structure of the coil is well known. Theoretical aspects are shortly reviewed at the end of the paper (Section 4). There is shown typical processes for data calculations leading to Zimm plot which yields to the molecular dimensions and solution thermodynamics [55-58]. All the data obtained for guanosines $\mathbf{1}$ and $\mathbf{2}$ are summarized in Table 1 .
TABLE 1: Molecular weights, radii of gyration, Virial coefficients, and Differential refraction indexes determined in chloroform solutions for guanosines $\mathbf{1}$ and 2. The experimental errors were determined to be $2 \%$ on $d n / d c$, and $10 \%$ on $A_{2},\left\langle R_{g}^{2}\right\rangle_{Z}^{1 / 2}$, and $\langle M\rangle_{W}$.

\begin{tabular}{|c|c|c|c|c|}
\hline & $\begin{array}{c}\langle M\rangle_{W} \\
\mathrm{~g} / \mathrm{mole}\end{array}$ & $\begin{array}{c}\left\langle R_{g}^{2}\right\rangle_{Z}^{1 / 2} \\
\mathrm{~nm}\end{array}$ & $\begin{array}{c}A_{2} \\
\mathrm{~mol} \mathrm{ml} / \mathrm{g}^{2}\end{array}$ & $d n / d c$ \\
\hline Guanosine 1 & 3620 & 57 & $3.510^{-4}$ & 0.0769 \\
\hline Guanosine 2 & $5.9310^{4}$ & 43 & $-6.410^{-4}$ & 0.083 \\
\hline
\end{tabular}

The Zimm plot obtained from guanosine $\mathbf{1}$ at $25^{\circ} \mathrm{C}$ in $\mathrm{CHCl}_{3}$ for different concentrations is shown in Figure 3. In this range of concentration, the apparent molecular weight was determined to be relatively stable below the gelation threshold. The linear regression reveals a modest molecular weight of 3620 (corresponding to an aggregation number of 6 to 7 units) but with a radius of gyration of $57 \mathrm{~nm}$ which indicates the presence of large objects. The discrepancy between these two parameters is explained by the high polydispersity of the supramolecular polymer with an average of small ribbons together with a smaller population of large objects. Indeed, the gyration radius being determined from $M_{W}$, the importance of the large structures becomes predominant.

The molecular weight of the polymers depends largely on the concentration range and a study between $2.8810^{-3}$ and $2.8810^{-2} \mathrm{~g} \cdot \mathrm{mL}^{-1}$ reveals a power law of 0.75 (see Figure 4) which is higher than the value (0.6) for regular swollen coils and which is the signature for rigid objects of about $200 \mathrm{~nm}$ in length [57, 62].

Finally, the association constant $K_{0}$ between two monomers in the supramolecular B-type ribbon (see Figure $1(\mathrm{c})$ ) was determined by plotting the apparent molecular weight as a function of the concentration (Figure 5) and shows a relatively small value $K_{0}=400 \mathrm{~L} \mathrm{~mol}^{-1}[59$, $60]$.

When the polymer is homogeneous, Flory Krigbaum [63] derived the more realistic model for $A_{2}$ introducing the $\kappa$ enthalpy and $\psi$ entropy parameter, respectively. By comparison with the Flory-Huggins theory [64] these parameters are seen to be related by $\psi-\kappa=(1 / 2)-\chi$ where $\chi$ is the Flory Huggins interaction parameters. For ideal behaviour $\psi=\kappa$ and $A_{2}=0$ so the theta point is reached, with theta temperature being given by $\theta=T(\kappa / \psi)$ where $T$ is the absolute temperature. The theory leads to some basics which are the equivalent size of the solvent and monomers, respectively, and a number of association for statistical calculations.

These statistical basics hold for guanosine 2 but comments on guanosine $\mathbf{1}$ may lie in the expression of idealized lattice model for second virial coefficient. It is obvious that one of the optimal conditions for association is an athermal solution which is what we have found for guanosine 2 (Table 1 ). In the case of guanosine 2 , the light scattering reveals a quite different behavior of the self-assembly process. The Zimm plot in Figure 6 shows a smaller polidispersity 


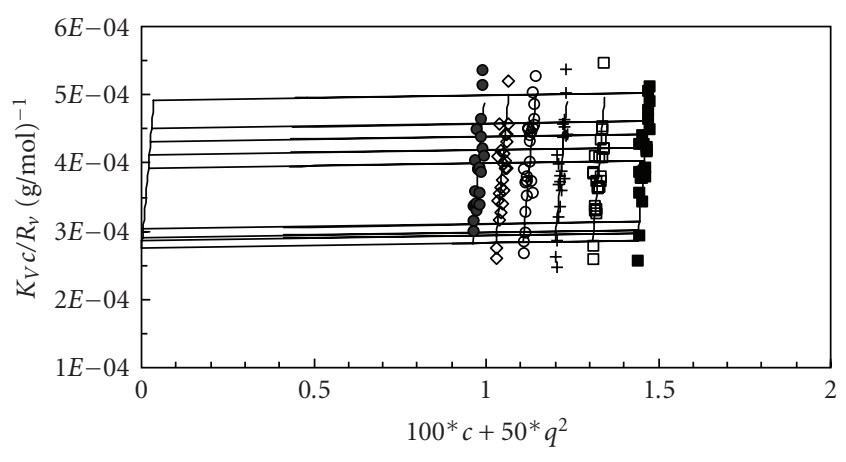

Figure 3: Zimm analysis by a two-power law linear regression (full line) which yields to the molecular size for molecule 1 from both extrapolations to $q, c \rightarrow 0 . M_{W}=3620$ dalton and $\left\langle R_{g}^{2}\right\rangle_{Z}^{1 / 2}=$ $57 \mathrm{nmA}_{2}=3.510^{-4} \mathrm{~mol} \mathrm{ml} / \mathrm{g} 2(\boldsymbol{\square})=1.4410^{-2} \mathrm{~g} / \mathrm{ml} ;(\square)=$ $1.3110^{-2} \mathrm{~g} / \mathrm{ml} ;(+)=1.210^{-2} \mathrm{~g} / \mathrm{ml} ;(\bigcirc)=1.1110^{-2} \mathrm{~g} / \mathrm{ml} ;(\diamond)=$ $1.0310^{-2} \mathrm{~g} / \mathrm{ml} ;(\bullet)=9.610^{-3} \mathrm{~g} / \mathrm{ml}$.

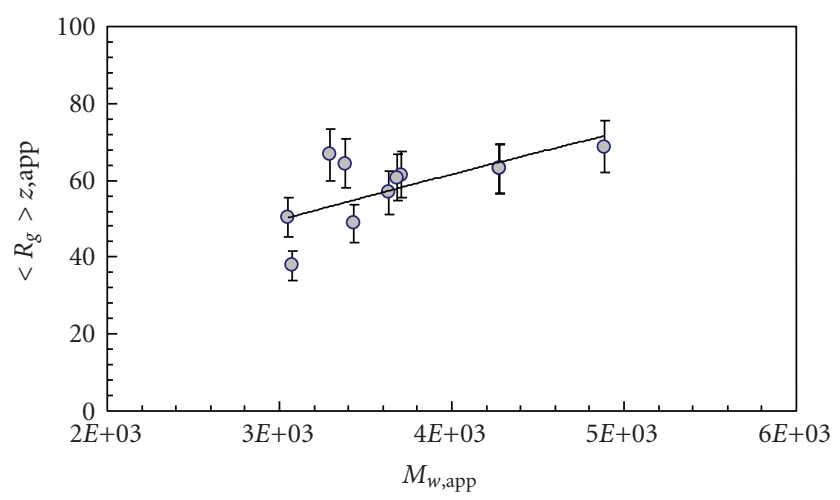

FIgURE 4: The experimental power law for guanosine $\mathbf{1}$ is 0.75 , higher than the value for regular swollen coil 0.6 (for the apparent Molecular weight $(\mathbf{)})$ ) and is the signature for a rigid object (error bars of $10 \%) .\langle\operatorname{Rg}\rangle z$,app is a statistical value of the gyration radius depending on the mass and number of monomers in the polymer (see [64]).

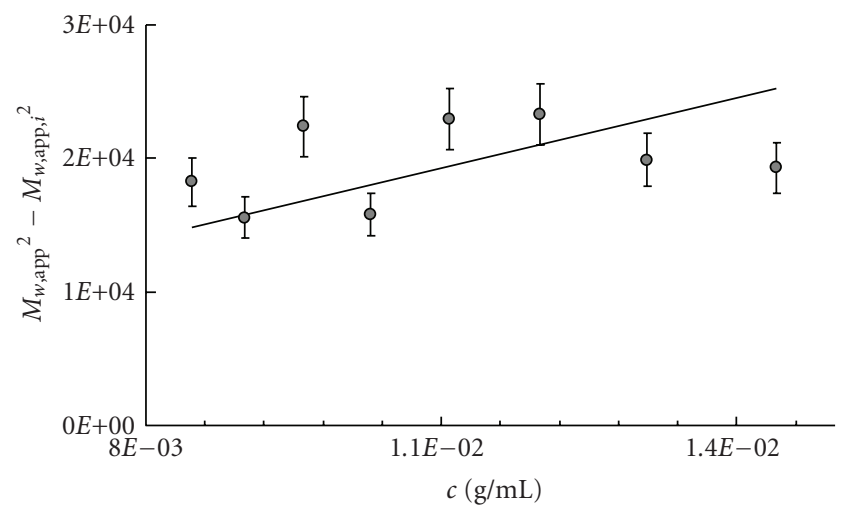

FIGURE 5: Determination of the equilibrium constant in the polymerization of $1 . M_{w, \text { app }, i}$ is the molecular weight of the initial monomer 1 starting the association. The guiding line shows the experimental points' regular behaviour. From the straight line it is possible to calculate the equilibrium constant of the association $K_{0}=400 \mathrm{~L} \mathrm{~mol}^{-1}$ (error bars of $\left.10 \%\right)$. than what is measured for guanosine $\mathbf{1}$ together with higher molecular weights $\left(M_{W}=5.9310^{4}\right.$, and the degree of polymerisation $\left.D_{p}=1250\right)$, but with a close radius of gyration $(43 \mathrm{~nm})$ which might correlate with the formation of more compact objects. This expectation is confirmed by plotting the $M_{W}$ in the range of concentration $3.410^{-3}$ and $6.8210^{-3} \mathrm{~g} \cdot \mathrm{mL}^{-1}$. The experimentally determined power law of 0.3 (see Figure 7) is the signature for very compact objects such as spheres [57,62]. Finally, the determination of the equilibrium constant $[59,60]$ for guanosine 2 shows a strong association process $\left(K_{0}=6.7510^{5} \mathrm{~L} \mathrm{~mol}^{-1}\right)$ and a complex behaviour of a sigmoid type (Figure 8). This nonlinear effect indicates a cooperative process and the hierarchical association between the linear supramolecular ribbons with their organization in higher-ordered selfassembled structures that in turn stabilize the primary association.

2.2. Transmission Electron Microscopy. Structural observation of self-assembled system can easily be achieved by TEM approaches, as widely used and described in the literature $[65,66]$.

Guanosine derivative $\mathbf{1}$ in bromoform $\left(1.4410^{-2} \mathrm{~g}\right.$. $\mathrm{mL}^{-1}$ ) forms small short fibers (Figure 9(a)). Bromoform was used for technical reasons regarding the evaporation rate at room temperature which is too high for chloroform thus changing the concentration of the sample during the preparation step. The dielectric constants are very close to each other for chloroform and bromoform (4,8 and 4,4 at $20^{\circ} \mathrm{C}$, resp.), and the gelation concentration was observed to be similar in both cases. These fibers present a diameter of $6 \mathrm{~nm}$ and a length of approximatively $200 \mathrm{~nm}$. Indeed, the precise length cannot be determined as the fibers present a high entanglement ratio. This length corresponds to the distance between the nodes of the networks and was also observed from time to time on individual filaments (see Figure 9(b)). It is also in agreement with the light scattering data. The small individual fibers self-assemble in larger ones to form bundles of $30 \mathrm{~nm}$. These latter can be formed during the preparation step as the diameter of the bundles varies from one experiment to another. The distribution of the fibers within a clear network illustrates the organogelator properties of guanosine $\mathbf{1}$.

Guanosine derivative 2 in bromoform $\left(410^{-3} \mathrm{~g} \cdot \mathrm{mL}^{-1}\right)$ forms small aggregates and small lamellar structures. On Figure 10, large aggregates consisting of the superposition of small $(100 \mathrm{~nm})$ lamellar structures are observed (see arrows). These structures show no define contours and are the results of the aggregations of the smaller domains. No internal features inside the small domains are visible at the resolution of the technique. The aggregation within highly compact lamellar structures is also in good agreement with the light scattering experiments that indicate mainly the presence of pseudospherical objects with a strong cooperative effect occurring between the ribbons and their higher-scale selfassemblies. 


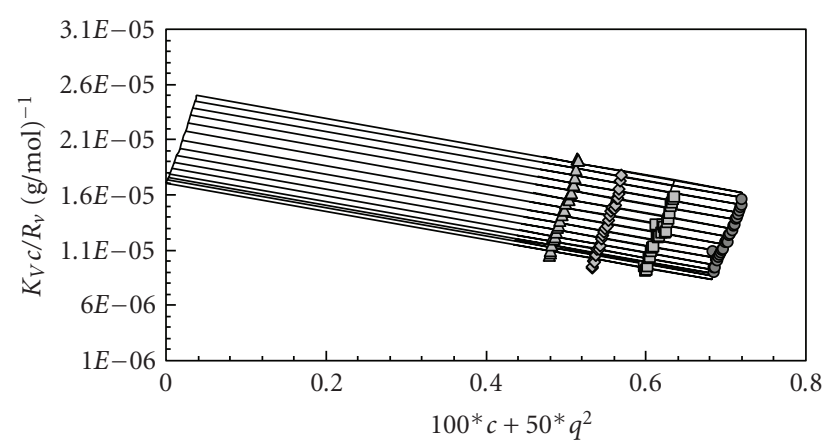

FIGURE 6: Zimm analysis by a two-power law linear regression (full line) which yields to the molecular size for molecule 2 from both extra polations to $q, c \rightarrow 0 . M_{W}=5.9310^{4}$ Dalton and $\left\langle R_{\mathrm{g}}^{2}\right\rangle_{Z}^{1 / 2}=$ $43 \mathrm{nmA}_{2}=-6.410^{-4} \mathrm{~mol} \mathrm{ml} / \mathrm{g}^{2}(\bullet)=6.8210^{-3} \mathrm{~g} / \mathrm{ml} ;(\boldsymbol{\square})=5.97$

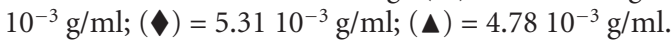

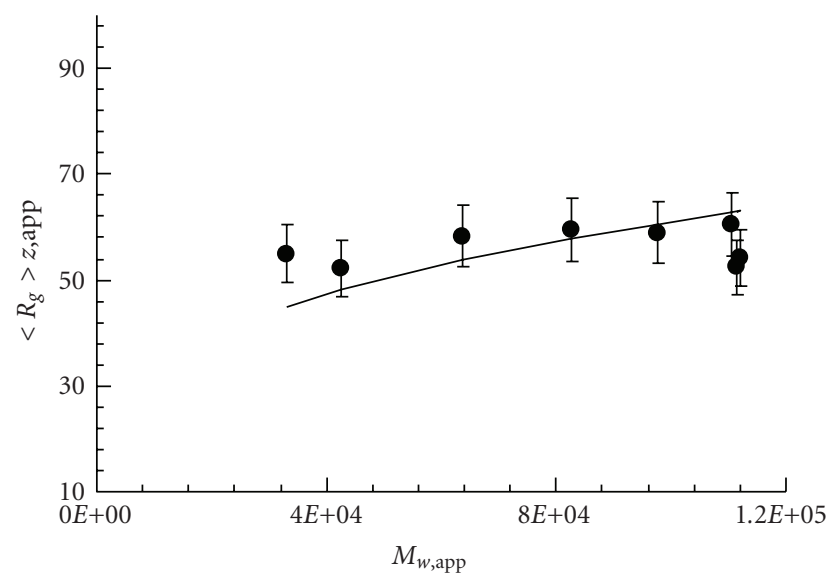

Figure 7: The experimental power law for guanosine 2 is 0.3 for the apparent Molecular weight ( ). The result shows a signature of very compact object and is the value for an athermal binary solution as ascertained by the low value for $A_{2}$, the second virial coefficient (error bars of 10\%).

\section{Conclusions}

We have determined the hierarchical polymeric natures of the self-assemblies obtained from the ribbon forming $[40,41]$ guanosine derivatives 1 and 2 . The light scattering measurements appeared as an appropriate technique for the molecular weight determination versus the structure of these objects that are both concentration sensitive. The main conclusions were confirmed by TEM. Lipophilic guanosine 1 forms very soft fibrillar objects of $6 \mathrm{~nm}$ of diameter and $200 \mathrm{~nm}$ in length and that in turn produces bundles of networked fibers with $30 \mathrm{~nm}$ of diameter. Despite its closely related structure, guanosine 2 forms much longer ribbons with molecular weights up to $610^{5}$ that in turn fold in very compact aggregates with lamellar structures. This process has been shown to be highly cooperative by the determination of the molecular weight as a function of the concentration.

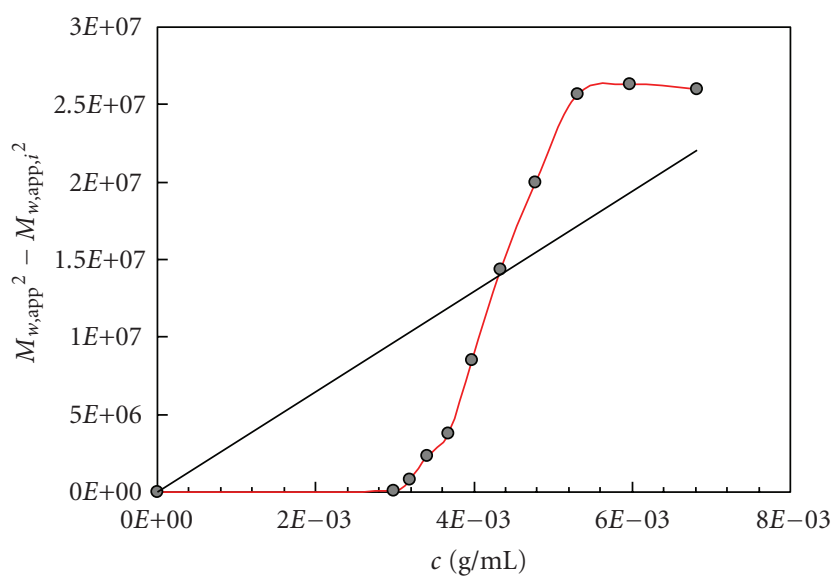

Figure 8: Determination of $K_{0}$ for compound 2. $M_{w, \text { app }, i}$ is the molecular weight of the initial monomer starting the association $[59,60]$. The red guiding line shows the experimental points' sigmoïdal behaviour. From the straight line, extrapolated for a noncooperative association, it is possible to calculate the mean equilibrium constant of the association $K_{0}=6.710^{5} \mathrm{~L} \mathrm{~mol}^{-1}$.

Interestingly, while both derivatives show the same motif of H-bonding in the formation of the first level of supramolecular assembly (the B-type ribbon), their hierarchical organization is quite different. This finding points out the role of other structural aspects in addition to the $\mathrm{H}$-bond recognition pattern (e.g., the number and length of tails) in determining the shape and dimension of the object obtained at the nanoscale level.

These investigations furnish an explanation to the gelation properties of these two derivatives and can be used to rationalize the synthesis of functional guanosine-based soft materials.

\section{Materials and Methods}

\subsection{Experimental Details for the Synthesis of Guanosine Derivatives}

3',5'-O-Didecanoyl-2'-Deoxyguanosine $\mathbf{1}$. Compound $\mathbf{1}$ was prepared in $94 \%$ yield starting from $2^{\prime}$-deoxyguanosine (Fluka) (1 mmol) and decanoic anhydride $(2.2 \mathrm{mmol})$ according to the literature procedure for $3^{\prime}, 5^{\prime}$-O-dipropanyl$2^{\prime}$-deoxyguanosine [67]. ${ }^{1} \mathrm{H}$ NMR $(300 \mathrm{MHz}$, [D6]DMSO): $\delta=0.84-0.86(\mathrm{tt}, 6 \mathrm{H} ; 2 \mathrm{CH} 3), 1.18-1.40(\mathrm{~m}, 24 \mathrm{H} ; 12 \mathrm{CH} 2)$, $1.40-1.60$ (m, 4H; 2 CH2-CH2-CO), 2.35-2.36 (tt, 4H; 2 $\mathrm{CH} 2-\mathrm{CO}), 2.42$ and $2.93\left(\mathrm{~mm}, 2 \mathrm{H}, \mathrm{H}-2^{\prime} / \mathrm{H}-2^{\prime \prime}\right), 4.19-4.38$ (m, 3H; H-4'/H-5'/H-5'), 5.35 (m, 1H; H-3'), 6.17 (m, 1H; H-1'), 6.45 (bs, 2H; NH2), 7.9 (s, 1H; H-8), 10.65 (s, 1H; NH); ES-MS: m/z (\%): $576.8(100)\left[\mathbf{1}^{+}+\mathrm{H}\right]$.

$2^{\prime}, 3^{\prime}$-O-Isopropylidene-5'-Decanoylguanosine 2. Compound 2 was prepared in $86 \%$ yield starting from $2^{\prime}, 3^{\prime}-O-$ isopropylideneguanosine (Sigma) $(0.77 \mathrm{mmol})$ and decanoic anhydride (1.2 equiv) according to the literature procedure [41]. 


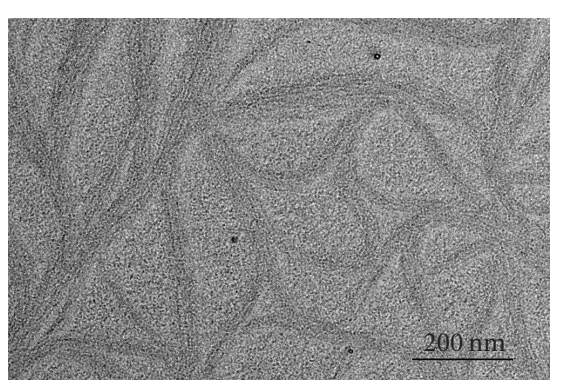

(a)

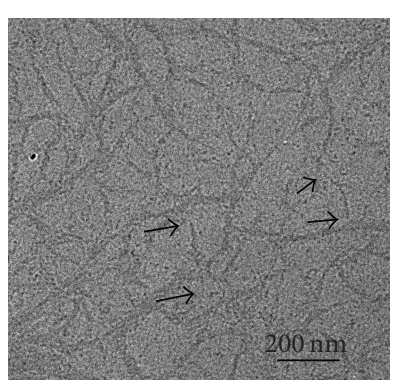

(b)

FIGURE 9: (a) TEM image of guanosine derivative 1 showing bundles of fibers. (b) Picture of compound $\mathbf{1}$ of individual fibers observed in a more dispersed area. The length of the fibers, which is close to $200 \mathrm{~nm}$, can only be measured on a very small number as they show a high tendency to fusion to form larger and entangled fibers.

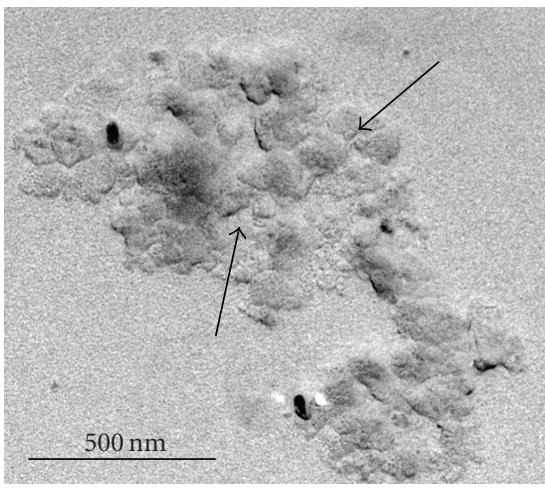

FIGURE 10: TEM image of guanosine derivative 2 .

4.2. Experimental Details Concerning the Static Light Scattering Technique. The light scattering experiments were carried out with an in-house apparatus [61] equipped with (i) a red He-Ne laser of wavelength $\lambda_{0}=632.8 \mathrm{~nm}$ in vacuum, (ii) a discrete-angle goniometer acting within the range from $20^{\circ}$ to $155^{\circ}$, (iii) a Hamamatsu type photomultiplier as detector, (iv) a photocounting device, and (v) a toluene matching bath. The vertical polarization of the incident beam with respect to the scattering plane has been used and is written $V$. The analyzer, arranged between the measuring cell and the photomultiplier, is vertically oriented and is written $V_{V}$. This optical setup allows measurement of the isotropic $V_{V}$ scattering intensity [68]. The excess of light scattering intensity $V_{V}(q)=V_{V \text { solution }}-V_{V \text { solvent }}$ was measured as a function of scattering vector $q=\left(4 \pi n / \lambda_{0}\right) \sin (\theta / 2)$ with an accuracy of $1 \%$ ( $\theta$ the scattering angle, $n$ the solvent refractive index). The values of Rayleigh excess scattering intensity $R(q)$ were obtained through the calibration of $V_{V}(q)$ with a benzene standard. The intensities $V_{V}(q)$, after normalization of the raw data, can be written $R_{V}$ for the vertically polarized scattering light through an analyzer.

Use the following formula for stray light $R_{v}$ :

$$
R_{V}=K_{V} * c * M_{W} * P(q) * S(q),
$$

where $M_{W}$ is the molecular weight, $c$ is the concentration of the polymer, $P(q)$ is the form factor, and $S(q)$ the long range interference from distant scatterers, where for dilute solution $S(q) \sim 1$ and $K_{V}$ is the optical factor for the system including the refractive index increment of the polymer as follows, where $K_{V}=K_{V \text { benzene }}(d n / d c)^{2}$ is the optical contrast calibrated with benzene standard (the suffix gives the polarization of incident beam and stray light).

The calibration of the spectrometer was made by evaluating the optical constant $K_{V}$ or $K_{V, V}$ as follows:

$$
K_{V}=\frac{4 \pi^{2} n_{\text {ref }}^{2}}{R_{V, \text { ref }} N_{A} \lambda_{0}^{4}} .
$$

$N_{A}$ is Avogadro Number, $\lambda_{0}$ is the wavelength in vacuum, $n_{\text {ref }}$ is the benzene refractive index, and $R_{V \text {,ref }}$ is the benzene Rayleigh ratio for vertically polarised incident light.

The chloroform refractive index and the average refractive index increment of the assembly for 1 to $\mathrm{CHCl}_{3}$ are equal to $n=1.4459$ and $d n / d c=0.0769 \mathrm{ml} / \mathrm{g}$, respectively.

The chloroform refractive index and the average refractive index increment of the assembly for 2 to $\mathrm{CHCl}_{3}$ are equal to $n=1.4459$ and $d n / d c=0.0830 \mathrm{ml} / \mathrm{g}$ respectively.

According to Yamakawa [62] the ratio $K_{V} c / R_{V}$ may be read versus $q$ as

$$
\frac{K_{V} c}{R_{V}}=\frac{1}{M_{W} P(q)}\left(1+A_{2} M_{W} c\right)^{2},
$$

where $R_{V}$ is the normalized scattering intensity from vertically incident beam analyzed vertically, and $A_{2}$ is the second virial coefficient.

Using the formalism of Debye [55] and Zimm [56], (2) gives the following:

$$
\frac{K_{V} c}{\Delta R_{V}}=M_{W}^{-1} P^{-1}(q)+2 A_{2} c .
$$

$\Delta R_{v}$ is the excess Rayleigh ratio of the polymer comparatively to the solvent. The inverse of the form factor $P^{-1}(q)$ leads after a MacLaurin transform at low $q$ vector to (5). Here we get $\left\langle R_{g}^{2}\right\rangle_{z}$ the second moment of the mass distribution which is the statistic $z$ average mean radius of gyration $[57,58]$ as follows:

$$
\frac{K_{V} c}{\Delta R_{V}}=M_{W}^{-1}\left(1+\frac{q^{2}\left\langle R^{2}\right\rangle_{z}}{3}+\cdots\right)+2 A_{2} c .
$$


For extrapolation at $q^{2} \rightarrow 0$ and $C \rightarrow 0$ (4) leads to the determination of the molecular mass and the second virial coefficient $A_{2}$. When the thermodynamic forces applied on the coil equilibrate, we can write $A_{2}=0$. This athermal condition for binary mixture allows the determination of the apparent molecular mass $M_{W \text {,app }}$ for each concentration $[59,60]$ :

$$
\frac{K_{V} c}{\Delta R_{V}}=M_{w, \text { app }}^{-1}\left(1+\frac{q^{2}\left\langle R^{2}\right\rangle_{z}}{3}\right) \pm \cdots .
$$

Equation (6) contains all information on the shape and the conformation of the isolated polymer in solution. The determination of the radius of gyration is only valid in the guinier range $q R<1$ where the architectures of the polymers are barely distinguishable.

The plot of (5) versus $k^{\prime} q^{2}+k^{\prime \prime} c$, called Zimm-plot, allows a simultaneous extrapolation to $q=0$ and $c=$ 0 , which yields $M_{W}^{-1}\left(\mathrm{~g} \cdot \mathrm{mol}^{-1}\right)$ as the ordinate intercept and $\left\langle R_{g}^{2}\right\rangle_{Z}^{1 / 2}$ as the initial slope of (6) and the second viral coefficient $\mathrm{A}_{2}$ from (5).

The value of the second viral coefficient $\mathrm{A}_{2}$ is in our case of an athermal binary mixture and thus neglected:

$$
\operatorname{Lim}_{(q \rightarrow 0)} \frac{K c}{\Delta R_{V}}=M_{w, \text { app }}^{-1}
$$

So we get a good evaluation of the variation for $M_{w, \text { app }}$ versus the concentration $C$.

Following the calculation of Huglin [59] and Elias [60] we obtain

$$
M_{w, \text { app }}^{2}-M_{w, \text { app }, i}^{2}=4000\left(K_{0} M_{w, \text { app }, i}\right) c .
$$

Here $M_{w, \text { app }, i}$ is the molecular weight of the initial monomer and $M_{w \text {,app }}$ is the weight average molecular weight determined through (7).

Measurements of each sample have been carried out after various dilutions with precise volume of clarified solvent obtained by filtration through millipore filters size $0.45 \mu \mathrm{m}$. All the samples are directly processed in the measurements vial to avoid dust pollution.

4.3. Experimental Details Concerning the TEM Technique. The samples are prepared in standard conditions as described in literature [69].

\section{Acknowledgments}

This work was supported by the COST Network G4-NET (MPNS Action MP0802). P. Neviani thanks the University of Bologna for a Marco Polo Fellowship supporting his staying in Strasbourg. N. Giuseppone and M. Schmutz thank the icFRC for financial support.

\section{References}

[1] J.-M. Lehn, "Perspectives in supramolecular chemistry-from the lock-and-key image to the information," Perspectives in Supramolecular Chemistry, vol. 1, pp. 307-317, 1994.
[2] F. J. M. Hoeben, P. Jonkheijm, E. W. Meijer, and A. P. H. J. Schenning, "About supramolecular assemblies of $\pi$ conjugated systems," Chemical Reviews, vol. 105, no. 4, pp. 1491-1546, 2005.

[3] D. S. Lawrence, T. Jiang, and M. Levett, "Self-assembling supramolecular complexes," Chemical Reviews, vol. 95, no. 6, pp. 2229-2260, 1995.

[4] A. Ajayaghosh, S. J. George, and A. P. H. J. Schenning, "Hydrogen-bonded assemblies of dyes and extended $\pi$ conjugated systems," Topics in Current Chemistry, vol. 258, pp. 83-118, 2005.

[5] T. F. A. de Greef and E. W. Meijer, "Materials science: supramolecular polymers," Nature, vol. 453, no. 7192, pp. 171-173, 2008.

[6] P. Cordier, F. Tournilhac, C. Soulié-Ziakovic, and L. Leibler, "Self-healing and thermoreversible rubber from supramolecular assembly," Nature, vol. 451, no. 7181, pp. 977-980, 2008.

[7] R. Nguyen, E. Buhler, and N. Giuseppone, "Dynablocks: structural modulation of responsive combinatorial self-assemblies at mesoscale," Macromolecules, vol. 42, no. 16, pp. 5913-5915, 2009.

[8] L. Tauk, A. P. Schröder, G. Decher, and N. Giuseppone, "Hierarchical functional gradients of $\mathrm{pH}$-responsive selfassembled monolayers using dynamic covalent chemistry on surfaces," Nature Chemistry, vol. 1, no. 8, pp. 649-656, 2009.

[9] M. Schmittel and V. Kalsani, "Functional, discrete, nanoscale supramolecular assimblies," Topics in Current Chemistry, vol. 245, pp. 1-53, 2005.

[10] S. Yagai, T. Seki, T. Karatsu, A. Kitamura, and F. Würthner, "Transformation from $\mathrm{H}$ - to J-aggregated perylene bisimide dyes by complexation with cyanurates," Angewandte Chemie International Edition, vol. 47, no. 18, pp. 3367-3371, 2008.

[11] P. G. A. Janssen, J. Vandenbergh, J. L. J. Van Dongen, E. W. Meijer, and A. P. H. J. Schenning, "ssDNA templated selfassembly of chromophores," Journal of the American Chemical Society, vol. 129, no. 19, pp. 6078-6079, 2007.

[12] A. Piermattei, M. Giesbers, A. T. M. Marcelis et al., "Induction of liquid crystallinity by self-assembled molecular boxes," Angewandte Chemie International Edition, vol. 45, no. 45, pp. 7543-7546, 2006.

[13] D. B. Amabilino and J. Veciana, "Supramolecular chiral functional materials," Topics in Current Chemistry, vol. 265, pp. 253-302, 2006.

[14] L. Brunsveld, B. J. B. Folmer, E. W. Meijer, and R. P. Sijbesma, "Supramolecular polymers," Chemical Reviews, vol. 101, no. 12, pp. 4071-4097, 2001.

[15] B. L. Feringa, R. A. Van Delden, N. Koumura, and E. M. Geertsema, "Chiroptical molecular switches," Chemical Reviews, vol. 100, no. 5, pp. 1789-1816, 2000.

[16] K. Kinbara and T. Aida, "Toward intelligent molecular machines: directed motions of biological and artificial molecules and assemblies," Chemical Reviews, vol. 105, no. 4, pp. 1377-1400, 2005.

[17] S. Yagai and A. Kitamura, "Recent advances in photoresponsive supramolecular self-assemblies," Chemical Society Reviews, vol. 37, no. 8, pp. 1520-1529, 2008.

[18] G. P. Spada, "Alignment by the convective and vortex flow of achiral self-assembled fibers induces strong circular dichroism effects," Angewandte Chemie International Edition, vol. 47, no. 4, pp. 636-638, 2008.

[19] S. Sivakova and S. J. Rowan, "Nucleobases as supramolecular motifs," Chemical Society Reviews, vol. 34, no. 1, pp. 9-21, 2005. 
[20] J. T. Davis and G. P. Spada, "Supramolecular architectures generated by self-assembly of guanosine derivatives," Chemical Society Reviews, vol. 36, no. 2, pp. 296-313, 2007.

[21] G. Gottarelli, S. Masiero, and G. P. Spada, "Self-assembly in organic solvents of a deoxyguanosine derivative induced by alkali metal picrates," Journal of the Chemical Society, Chemical Communications, no. 24, pp. 2555-2557, 1995.

[22] J. T. Davis, S. Tirumala, J. R. Jenssen, E. Radler, and D. Fabris, "Self-assembled ionophores from isoguanosine," Journal of Organic Chemistry, vol. 60, no. 13, pp. 4167-4176, 1995.

[23] C. Arnal-Hérault, A. Banu, M. Barboiu, M. Michau, and A. van der Lee, "Amplification and transcription of the dynamic supra-molecular chirality of the guanine quadruplex," Angewandte Chemie International Edition, vol. 46, no. 23, pp. 42684272, 2007.

[24] S. Martic, X. Liu, S. Wang, and G. Wu, "Self-assembly of $\mathrm{N}^{2}$-modified guanosine derivatives: formation of discrete Goctamers," Chemistry, vol. 14, no. 4, pp. 1196-1204, 2008.

[25] I. C. M. Kwan, A. Wong, Y.-M. She, M. E. Smith, and G. Wu, "Direct NMR evidence for $\mathrm{Ca}^{2+}$ ion binding to G-quartets," Chemical Communications, no. 6, pp. 682-684, 2008.

[26] M. Nikan and J. C. Sherman, "Template-assembled synthetic G-quartets (TASQs)," Angewandte Chemie International Edition, vol. 47, no. 26, pp. 4900-4902, 2008.

[27] L. Ma, M. Melegari, M. Colombini, and J. T. Davis, "Large and stable transmembrane pores from guanosine-bile acid conjugates," Journal of the American Chemical Society, vol. 130, no. 10, pp. 2938-2939, 2008.

[28] A. Likhitsup, S. Yu, Y.-H. Ng, C. L.L. Chai, and E. K.W. Tam, "Controlled polymerization and self-assembly of a supramolecular star polymer with a guanosine quadruplex core," Chemical Communications, no. 27, pp. 4070-4072, 2009.

[29] M. D. C. Rivera-Sánchez, I. Andújar-de-Sanctis, M. GarcíaArriaga, V. Gubala, G. Hobley, and J. M. Rivera, "Walking a supramolecular tightrope: a self-assembled dodecamer from an 8-aryl-2'-deoxyguanosine derivative," Journal of the American Chemical Society, vol. 131, no. 30, pp. 10403-10405, 2009.

[30] D. González-Rodriguez, J. L. J. van Dongen, M. Lutz, A. L. Spek, A. P. H. J. Schenning, and E. W. Meijer, "G-quadruplex self-assembly regulated by Coulombic interactions," Nature Chemistry, vol. 1, no. 2, pp. 151-155, 2009.

[31] S. Lena, P. Neviani, S. Masiero, S. Pieraccini, and G. P. Spada, "Triggering of guanosine self-assembly by light," Angewandte Chemie International Edition, vol. 49, no. 21, pp. 3657-3660, 2010.

[32] M. S. Kaucher, W. A. Harrell Jr., and J. T. Davis, "The Gquartet in supramolecular chemistry and nanoscience," in Quadruplex Nucleic Acids, S. Neidle and S. Balasubramanian, Eds., chapter 10, pp. 253-290, RSC Publishing, Cambridge, UK, 2006.

[33] S. Neidle and S. Balasubramanian, Eds., Quadruplex Nucleic Acids, RSC Publishing, Cambridge, UK, 2006.

[34] J. L. Huppert, "Four-stranded nucleic acids: structure, function and targeting of G-quadruplexes," Chemical Society Reviews, vol. 37, no. 7, pp. 1375-1384, 2008.

[35] D. Monchaud and M.-P. Teulade-Fichou, "A hitchhiker's guide to G-quadruplex ligands," Organic and Biomolecular Chemistry, vol. 6, no. 4, pp. 627-636, 2008.

[36] J. T. Davis, "G-quartets 40 years later: from 5'-GMP to molecular biology and supramolecular chemistry," Angewandte Chemie International Edition, vol. 43, no. 6, pp. 668-698, 2004.

[37] S. Lena, S. Masiero, S. Pieraccini, and G. P. Spada, "Guanosine hydrogen-bonded scaffolds: a new way to control the bottom-up realisation of well-defined nanoarchitectures," Chemistry, vol. 15, no. 32, pp. 7792-7806, 2009.

[38] G. Gottarelli, S. Masiero, E. Mezzina, G. P. Spada, P. Mariani, and M. Recanatini, "The self-assembly of a lipophilic deoxyguanosine derivative and the formation of a liquidcrystalline phase in hydrocarbon solvents," Helvetica Chimica Acta, vol. 81, no. 11, pp. 2078-2092, 1998.

[39] G. Gottarelli, S. Masiero, E. Mezzina, S. Pieraccini, G. P. Spada, and P. Mariani, "A new lyotropic liquid crystalline phase formed in hydrocarbon solvents by a deoxyguanosine derivative through extensive hydrogen bonding," Liquid Crystals, vol. 26, no. 7, pp. 965-971, 1999.

[40] G. Gottarelli, S. Masiero, E. Mezzina et al., "The self-assembly of lipophilic guanosine derivatives in solution and on solid surfaces," Chemistry, vol. 6, no. 17, pp. 3242-3248, 2000.

[41] T. Giorgi, F. Grepioni, I. Manet et al., "Gel-like lyomesophases formed in organic solvents by self-assembled guanine ribbons," Chemistry, vol. 8, no. 9, pp. 2143-2152, 2002.

[42] S. Lena, G. Brancolini, G. Gottarelli et al., "Self-assembly of an alkylated guanosine derivative into ordered supramolecular nanoribbons in solution and on solid surfaces," Chemistry, vol. 13, no. 13, pp. 3757-3764, 2007.

[43] T. N. Pham, J. M. Griffin, S. Masiero et al., "Quantifying hydrogen-bonding strength: the measurement of $2 \mathrm{hJNN}$ couplings in self-assembled guanosines by solid-state $15 \mathrm{~N}$ spinecho MAS NMR," Physical Chemistry Chemical physics, vol. 9, no. 26, pp. 3416-3423, 2007.

[44] S. A. Joyce, J. R. Yates, C. J. Pickard, and S. P. Brown, "Density functional theory calculations of hydrogen-bond-mediated NMR J coupling in the solid state," Journal of the American Chemical Society, vol. 130, no. 38, pp. 12663-12670, 2008.

[45] G. P. Spada, S. Lena, S. Masiero, S. Pieraccini, M. Surin, and P. Samorì, "Guanosine-based hydrogen-bonded scaffolds: controlling the assembly of oligothiophenes," Advanced Materials, vol. 20, no. 12, pp. 2433-2438, 2008.

[46] A. Ciesielski, S. Lena, S. Masiero, G. P. Spada, and P. Samorì, "Dynamers at the solid-liquid interface: controlling the reversible assembly/reassembly process between two highly ordered supramolecular guanine motifs," Angewandte Chemie International Edition, vol. 49, no. 11, pp. 1963-1966, 2010.

[47] G. Maruccio, P. Visconti, V. Arima, et al., "Field effect transistor based on a modified DNA base," Nano Letters, vol. 3, no. 4, pp. 479-483, 2003.

[48] R. Rinaldi, E. Branca, R. Cingolani, S. Masiero, G. P. Spada, and G. Gottarelli, "Photodetectors fabricated from a selfassembly of a deoxyguanosine derivative," Applied Physics Letters, vol. 78, no. 22, pp. 3541-3543, 2001.

[49] H. Liddar, J. Li, A. Neogi et al., "Self-assembled deoxyguanosine based molecular electronic device on GaN substrates," Applied Physics Letters, vol. 92, no. 1, Article ID 013309, 3 pages, 2008.

[50] K. Maekawa, D. Shiomi, T. Ise, K. Sato, and T. Takui, "A guanine-substituted nitronyl nitroxide radical forming a onedimensional ferromagnetic chain," Organic and Biomolecular Chemistry, vol. 5, no. 10, pp. 1641-1645, 2007.

[51] A. M. S. Kumar, S. Sivakova, J. D. Fox, J. E. Green, R. E. Marchant, and S. J. Rowan, "Molecular engineering of supramolecular scaffold coatings that can reduce static platelet adhesion," Journal of the American Chemical Society, vol. 130, no. 4, pp. 1466-1476, 2008.

[52] K. Araki and I. Yoshikawa, "Nucleobase-containing gelators," Topics in Current Chemistry, vol. 256, pp. 133-165, 2005.

[53] K. Araki, R. Takasawa, and I. Yoshikawa, "Design, fabrication, and properties of macroscale supramolecular fibers consisted 
of fully hydrogen-bonded pseudo-polymer chains," Chemical Communications, no. 18, pp. 1826-1827, 2001.

[54] A. M. S. Kumar, J. D. Fox, L. E. Buerkle, R. E. Marchant, and S. J. Rowan, "Effect of monomer structure and solvent on the growth of supramolecular nanoassemblies on a graphite surface," Langmuir, vol. 25, no. 2, pp. 653-656, 2009.

[55] P. Debye, "Molecular-weight determination by light scattering," Journal of Physical and Colloid Chemistry, vol. 51, no. 1, pp. 18-32, 1947.

[56] B. H. Zimm, "The scattering of light and the radial distribution function of high polymer solutions," The Journal of Chemical Physics, vol. 16, no. 12, pp. 1093-1099, 1948.

[57] H. C. Benoi and J. S. Higgins, Polymers and Neutron Scattering, Clarendon Press, Oxford, UK, 1994.

[58] B. Chu, Laser Light Scattering, Academic Press, London, UK, 2nd edition, 1991.

[59] M. B. Huglin, Light Scattering from Polymer Solutions, Academic Press, New York, NY, USA, 1972.

[60] H. G. Elias, "Specific refractive index increments," in Light Scattering from Polymer Solutions, M. B. Huglin, Ed., p. 428, Huglin Academic Press, London, UK, 1972.

[61] R. Libeyre, D. Sarazin, and J. François, "Automatized photogoniodiffusometer and coupling with automatized viscosimeter," Polymer Bulletin, vol. 4, no. 1-2, pp. 53-60, 1981.

[62] H. Yamakawa, Modern Theory of Polymer Solution, Harper and Row, New York, NY, USA, 1971.

[63] P. J. Flory and W. R. Krigbaum, "Statistical mechanics of dilute polymer solutions. II," The Journal of Chemical Physics, vol. 18, no. 8, pp. 1086-1094, 1950.

[64] P. J. Flory, Principles of Polymer Chemistry, Cornell University Press, New York, NY, USA, 1957.

[65] R. Schmidt, M. Schmutz, M. Michel, G. Decher, and P. J. Mésini, "Organogelation properties of a series of oligoamides," Langmuir, vol. 18, no. 15, pp. 5668-5672, 2002.

[66] A. Petitjean, L. A. Cuccia, M. Schmutz, and J.-M. Lehn, "Naphthyridine-based helical foldamers and macrocycles: synthesis, cation binding, and supramolecular assemblies," Journal of Organic Chemistry, vol. 73, no. 7, pp. 2481-2495, 2008.

[67] I. Manet, L. Francini, S. Masiero, S. Pieraccini, G. P. Spada, and G. Gottarelli, "An ESI-MS and NMR study of the self-assembly of guanosine derivatives," Helvetica Chimica Acta, vol. 84, no. 7, pp. 2096-2107, 2001.

[68] G. G. Fuller, Optical Rheometry of Complex Fluids: Theory and Practice of Optical Rheometry, Oxford University Press, Oxford, UK, 1995.

[69] V. Berl, M. J. Krische, I. Huc, J.-M. Lehn, and M. Schmutz, "Template-induced and molecular recognition directed hierarchical generation of supramolecular assemblies from molecular strands," Chemistry, vol. 6, no. 11, pp. 1938-1946, 2000. 

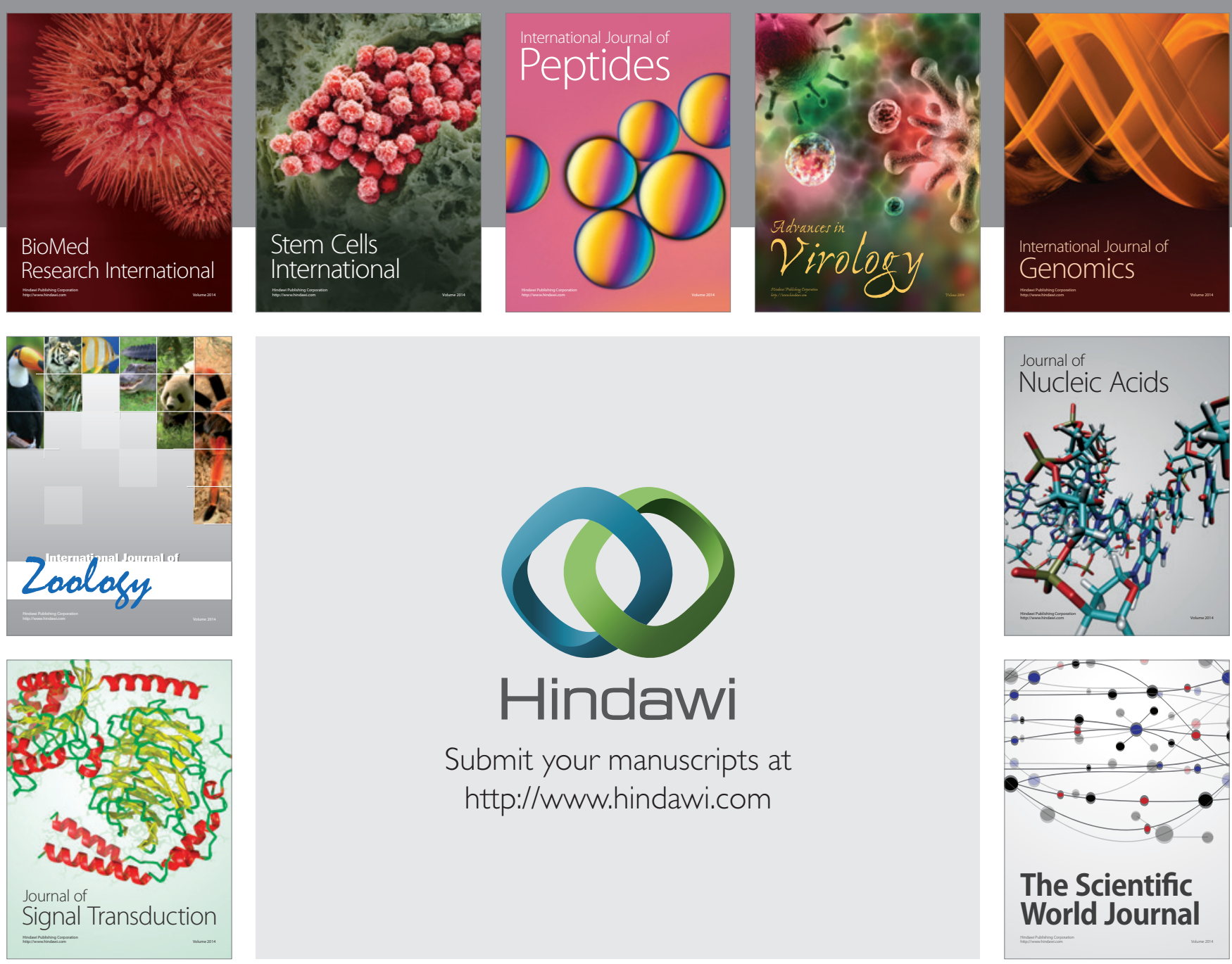

Submit your manuscripts at

http://www.hindawi.com
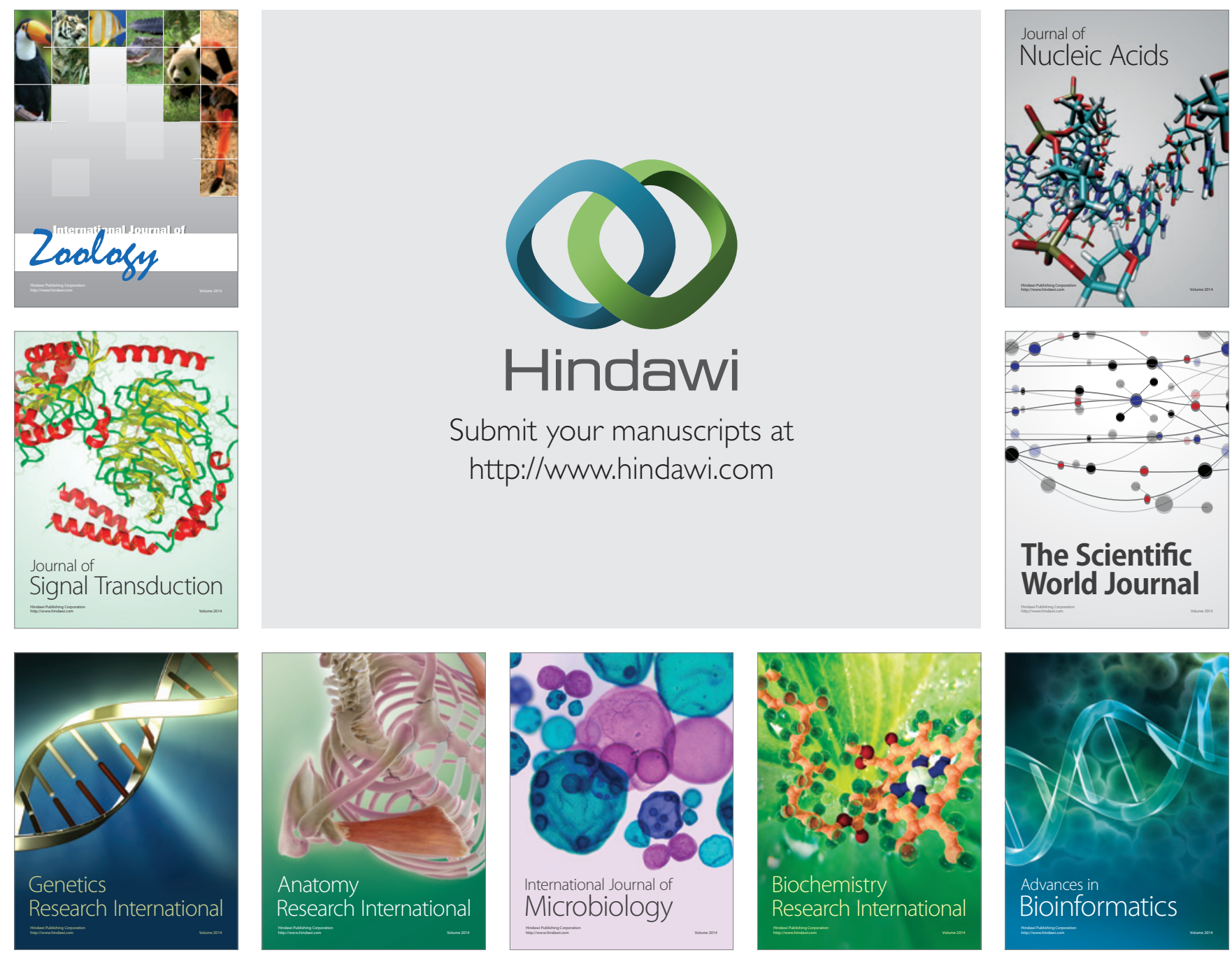

The Scientific World Journal
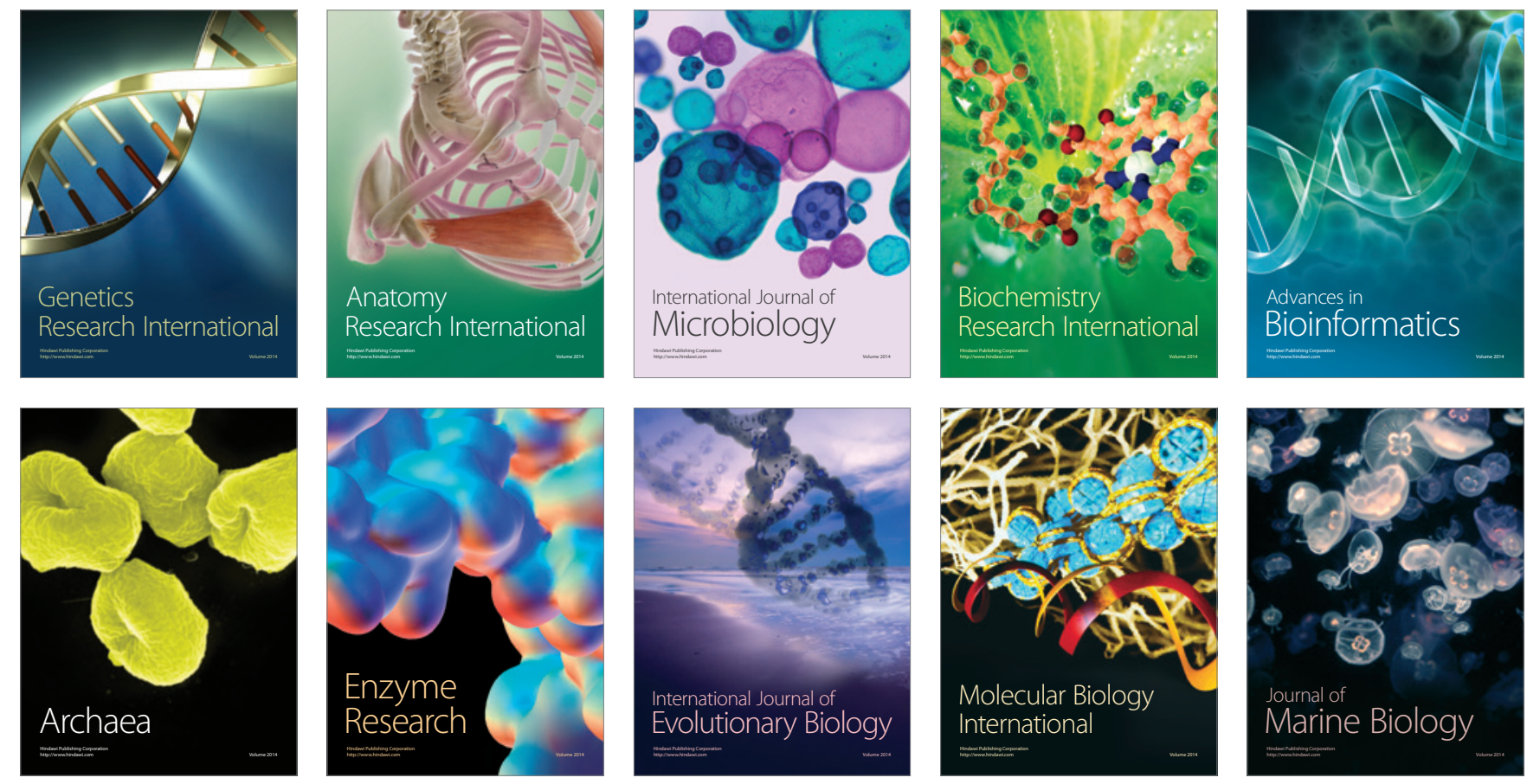